\title{
METODE PEMBINAAN AKHLAK MENURUT IBNU QAYYIM AL-JAUZI (1292-1352 M)
}

\author{
Nurhayati Hsy \\ STMIK Hang Tuah Pekanbaru \\ Tengkerang Selatan, Bukit Raya, Kota Pekanbaru \\ nurhayatihsy72@gmail.com \\ Suherman. S \\ STMIK Hang Tuah Pekanbaru, \\ Tengkerang Selatan, Bukit Raya, Kota Pekanbaru \\ suhermansohorgani@gmail.com
}

DOI: 10.46781/al-mutharahah.v18i2.360

\begin{abstract}
The method of moral development according to Ibn Qayyim Al-Jauzi is something that is very much needed in everyday needs, which in this globalized life, there are many moral decadencies. For the concept of fostering the character of Ibn Qayyim Al-Jauzi by studying and analyzing in forming a balanced human being (Tawazun) in the sense of a balance of fikriyah, ruhiyah and jasadiyah which be Ibnu qayyyim Al-Jauzirdas based on Al-qur'an and hadith. Ibn Qayyim Al-Jauzi argued that in order to achieve moral perfection a coaching method is needed through emptying and decorating oneself, activating children in doing good, training and habituation, giving a bad picture of the despicable morals and showing exemplary attitudes. The purpose of this research is to find out how the method of moral development according to Ibn Qayyim Al-Jauzi. This type of research is research based on library (Library Research) Ibnu Al-Qayyim al-jauzi.
\end{abstract}

Keywords: Methods of Guidance, Morals, Ibn Qayyim.

\begin{abstract}
Abstrak
Metode pembinaan akhlak menurut Ibnu Qayyim Al-Jauzi adalah merupakan suatu hal yang sangat dibutuhkan di dalam kehidupan sehari-hari, yang mana di dalam sistem informasi kehidupan yang serba globalisasi ini banyaknya terjadi berbagai dekadensi moral di dalam masyarakat. Untuk konsep pembinaan akhlak Ibnu Qayyim Al-Jauzi dengan menelaah serta menganalisa dalam membentuk manusia yang seimbang (Tawazun) dalam pengertian adanya keseimbangan fikriyah, ruhiyah dan jasadiyah yang beliau Ibnu qayyyim Al-Jauzi di dasarkan dari Al-qur'an dan Hadist. Ibnu Qayyim Al-Jauzi mengemukakan bahwa dalam rangka menuju kesempurnaan akhlak diperlukan metode pembinaan melalui pengosongan dan menghiasi diri, mengaktifkan anak dalam berbuat baik, pelatihan dan pembiasaan, memberi gambaran yang buruk tentang akhlak yang tercela dan menunjukkan sikap keteladanan. Tujuan penelitian adalah untuk mengetahui secara mendalam bagaimana metode pembinaan akhlak menurut Ibnu Qayyim Al-Jauzi dan Menggali pemikiran akhlak Ibnu Qayyim Al-Jauzi.
\end{abstract}

Kata Kunci: Metode Pembinaan, Akhlak, Ibnu Qayyim 


\section{A. Pendahuluan}

Manusia adalah satu diantara makhluk Allah yang paling baik penciptaannya bila dibandingkan dengan makhluk lainnya, hal ini dijelaskan oleh ayat Al-qur'an dan hadist nabi SAW, seperti firman NYA QS.95.4 yang artinya Sesungguhnya kami telah menciptakan manusia dalam bentuk yang sebaik-baiknya (QS. At-Tin, 95:4 ). Manusia sebagai makhluk yang baik penciptaannya memeliki beberapa kelebihan dari pada makhluk lainnya, diantaranya manusia memeliki akal yang berfungsi untuk berfikir yang mampu membedakan yang hak dan yang batil. Allah mengilhamkan kepada manusia jalan kefasikan dan ketaqwaan serta menanamkan kesiapan untuk berbuat kebaikan maupun kejahatan. Allah SWT menciptakan manusia bertujuan untuk menyembah kepada Allah, sebagai tempat meminta pertolongan, tempat berlindung, melakukan segala aktifitas hidup karena Alllah. Selain itu kelebihan kelebihan yang dimiliki oleh manusia pada awalnya bersumber kepada potensi (fitrah), fitrah itu sendiri selanjutnya akan berproses menuju pertumbuhan dan perkembangan seiring perkembangan fisik atau fisikis dan pengaruh lingkungan yang dialaminya. Dari unsur unsur penciptaan manusia, maka yang menjadi sasaran pendidikan tertuju pada tiga unsur yaitu ruh,akal dan jasad. Adapun sebagai barometer kehormatan dan kemuliaan manusia adalah akhlak, oleh karena itu seseorang harus dididik dan dibina dengan akhlak terpuji sehingga menjadi manusia yang berakhlak mulia. Tujuan penelitian ini adalah untuk membuktikan bahwa faktor-akhlak merupakan barometer yang berhubungan sangat penting dalam kehidupan sehari-hari menurut Ibnu Qayyim Al-Jauzi.

\section{B. Metode Penelitian}

Penelitian ini bersifat Studi perpustakaan dengan menggunakan desain yang berhubungan dengan penelitian ini, selain data sekunder, dan data primer dikumpulkan dari semua variabel melalui studi keperpustakaan baik yang berada di kampus UIN Suska Pekan baru maupun perpustakaan di luar kampus.

\section{Pembahasan}

Hasil dari penelitian tentang pembinanaan Akhlak menurut Ibnu qayyim Al Jauzi adalah termasuk permasaahan terpenting dalam kehidupan didunia ini tingkatnya berada setelah iman, kalau beriman dan beribadah kepada Allah hubungannya adalah antara hamba dan tuhannya, sedangkan akhlak selain hubungannya antara hamba dengan tuhannya, adalah hubungan dengan bermuamalah dengan bermusyarokah antara sesama manusia, juga mengatur hubungan manusia dengan segala yang terdapat dalam wujud kehidupan. Landasan pembinaan akhlak adalah Alqur'an dan hadist, ra'yu, qiyas dan ikhtihsan.

Tabel 1. Konsep akhlak Menurut Ibnu Qayyim Al-Jauzi

\begin{tabular}{|c|c|c|}
\hline NO & URAIAN & KETERANGAN \\
\hline 1. & Landasan Tujuan Akhlak & Al-qu'an dan hadist sbg \\
\hline & 1. Alqur'an & Landasan, sumber, dan dan tujuan hdp \\
\hline & 2. Al-hadist & manusia. \\
\hline 2. & Tujuan pembinaan Akhlak & Menjaga kesehatan badan \\
\hline & 1. Ahda jismiyah & Menjaga Akhlak mulia \\
\hline & 2. Ahdaf ahlakiyah & Menjaga akal \\
\hline & 3. Ahdaf fikriyah & Mengembangkan bakat dan keterampilan \\
\hline & 4. Ahdaf maslakiyah & \\
\hline 3. & $\begin{array}{l}\text { Kebutuhan manusia terhadap pendidikan } \\
\text { Akhlak }\end{array}$ & $\begin{array}{l}\text { Akhlakwajib diperhatikan sejak kecil sampai } \\
\text { dewasa }\end{array}$ \\
\hline 4. & $\begin{array}{l}\text { Pokok-pokok Keutamaan Akhlak } \\
\text { 1. Sabar }\end{array}$ & $\begin{array}{l}\text { Menahan jiwadari merasa marah, menahan } \\
\text { lisan, badan dari maksiat. }\end{array}$ \\
\hline
\end{tabular}




\begin{tabular}{|c|c|c|}
\hline 5. & \begin{tabular}{|l} 
2. Tawadhu \\
3. Khusyu \\
4. Malu (Al-Hayyu ) \\
5. Syukur \\
6. Itsyar (Mengutamakan \\
orang lain) \\
7. Siddiq \\
8. Ikhlas \\
Metode pembinaan akhlak ibnu qayyim \\
1. Pengosongan dan \\
menghiasi diri \\
2. Mengaktifkan anak \\
berbuat baik \\
3. Pelatihan dan pembiasaan \\
4. Memberikan gambaran \\
yang buruktentang akhlak \\
tercela \\
5. Adab
\end{tabular} & $\begin{array}{l}\text { Rendah hati, tdk sombong } \\
\text { Tunduk, tanang,rendah } \\
\text { Meninggalkan keburukan } \\
\text { Menyebut-nyebut nikmat Allah } \\
\text { Tanda cinta dan tanda ukhuwah }\end{array}$ \\
\hline
\end{tabular}

Sumber Data Olahan

\section{Konsep Akhlak Menurut Ibnu Qayyim Al-Jauzi}

Dari hasil penelitian, diketahui bahwa kepala keluarga memiliki sarana yang sangat penting dalam pembinaan akhlak dalam menjalani kehidupan dalam era gobalisasi yang penuh terjadi dekadensi moral. Dalam penelitian Muzaidi Abdulllah (2001), dimana penelitian tersebut menunjukkan bahwa ada hubungan bermakna antara manusia sebagai makhluk sosial yang tidak dapat hidup secara sempurna secara sendirian tanpa keterlibatan orang lain, oleh karena itu dalam berinteraksi dengan orang lain dapat berjalan harmonis dan baik, maka setiap indifidu selalu menghiasi hidupnya berprilaku Akhlak terpuji dan mulia yang dapat memuaskan hidup serta jiwa manusia.

\section{Hubungan Akhlak Dengan Pendidikan}

Dari hasil penelitian diketahui bahwa ada beberapa poin dari pendidikan akhlak menurut Ibnu Qayyyim Al-Jauzi antara lain :

a) Ahda jismiah yaitu berkaitan dengan kesehatan badan, sehinnga diwasiatkan Ibnu Qayyim Al- Jauzi kepada orang tua hendaklah bayi yang baru dilahirkan di susukan, bahwa air susu ibu yang berwarna putih kekuning - kuningan, bergetah yang keluar pada hari pertama mengandung nilai gizi yang sangat tingggi dalam pertumbuhan bayi.

b) Akhdaf Akhlakiyah yaitu berkaitan dengan kebahagian akan bisa di raih dengan terhiasinya pribadi dengan akhlak mulia.

c) Ahdaf fikriyah yaitu berkaitan dengan peningkatan kemampuan akal, artinya seorang anak tidak boleh diberi kesempatan untuk berinteraksi dengan hal hal yang merusak akalnya misalnya minuman keras yang memabukkan (Narkoba) .

d) Ahdaf Maslakiyah yaitu berkaitan memberikan kesempatan kepada anak untuk mengembangkan semua potensidn bakat yang tampak dalam diri anak, seperti dalam seni atau olah raga dansebagainya.

Pokok- pokok keutamaan akhlak menurut Ibnu Qayyim Al Jauzi yaitu :

a) Sabar adalah menahan jiwa dari merasa tidak menerima dan marah dengan takdir Alllah dan menahan lisan dari merintih (mengadu) serta menahan anggota badan dari maksiat. 
b) Tawadhu adalah rendah hati, Ibnu qayyim tawadhu ada $3: 1$. tawadhu terhadap agama artinya tidak menentangnya dengan pemikiran, 2 . tawadhu meredoi saudara sesama muslim sebagai saudara sesama hamba Allah, 3. Tawadhu tunduk seluruh aturan aturan kepada Allah.

c) Khusuk artinya adalah tunduk, rendah, dan tenang ketika di hadapan TuhanNya yang dilakukan secara bersamaan.

d) Al-Hayyu (Malu) adalah akhlak yang mendorong untuk meninggalkan keburukan dan melakukan kebaikan.

e) Syukur adalah mengandung 3 arti yaitu menghadirkan nikmat dalam pikiran dan mempersaksikan, kedua menerima nikmat artinya menerima dari pemberi nikmat , ketiga Memuji nikmat yaitu memuji pemberi nikmat.

f) Itsar (Mengutamakan kepentingan orang lain) yaitu orang yang mengutamakan orang lain berarti meninggalkan apa yang sebenarnya ia perlukan.

g) Shidiq dapat diartikan benar, jujur, lurus, tulus atau merupakan suatu yang harus ditempuh dan dicari oleh setiap muslim, sedangkan orang yang tidak berlaku benar berarti ia orang gagal dalam perjalanan hidupnya.

h) Ikhlas artinya adalah membersihkan perbuatan dari perhatian makhluk.

i) Ikhsan artinya yaitu hendaklah engkau menyembah Allah seakan-akan engkau dapat melihatnya dan meskipun engkau tidak melihatnya sesungguhnya Dia melihat engkau.

\section{Simpulan}

Dari penelitian yang telah dilakukan dapat diperoleh kesimpulan sebagai berikut:

1) Ibnu qayyim Al- Jauzi mengemukakan bahwa dalam rangka menuju kesempurnaan akhlak diperlukan metode pembinaan akhlak melalui pengesongan dan menghiasi diri, mengaktifkan anak dalam berbuat baik, pelatihan dan pembiasaan, memberi penjelasan dan gambaran yang buruk tentang akhlak yang tercela dan menunjukkan sikap keteladanan.

2) Ibnu qayyim Al-Jauzi bahwa titik awal dari keberhasilan dalam pembinaan akhlak terletak kepada orang atau pendidik dan anak atau murobbi, adab murobbi dapat dirumuskan dalam pemahaman yang mendalam, perlunya kehati-hatian (tasabut) mengamalkan ilmunya, berdakwah,dan dapat menjadi teladan bagi peserta anak didik.

3) Ibnu Qayyim Al- Jauzi Akhlak bertujuan untuk menjaga kesucian (fitrah) manusia dan melindunginya agar tidak jatuh kedalam perbuatan maksiatserta mewujudkan dalam dirinya ubudiyah kepada Allah SWT dengan ubudiyah yang benarakan melahirkan akhlak yang mulia..

4) Ibnu Qayyim Al-Jauzi bahwa masyarakat merupakan tempat interaksi sosial yang mempunyai peranan sangat besar dalam pembinaan indifidu, baik dari segi pemikiran , tingkah laku, maupun perasaan.

5) Akhlak merupakan bagian yang terk terpisahkan dari ibadah maupun mu'amalah, yang harus mendapatkan perhatian sejak usia dini untuk menghantarkan seseorang kepada keridoan Allah SWT. 


\section{DAFTAR PUSTAKA}

Abduh, Isa dan yahya, Ahmad Ismail, Hakikat al-Ikhsan, Beirud dar- al-Ma'arif, th

Al- Asfahani, Al- Raghib, Mu'jam al- Mufradat al-Faz Al- Qur'an, Beirut al-syamsiyah,1992

Al Hijas, Hasan Bin Ali Manhaj Tarbiyah Ibn Qayyim (Terj.Haidar Bagir Jalaluddin Rahmad) dari The Conceptof Education non Islam : A Framerwork for Islamic philosohyf of edocatialon, Bandung, Mizan, 1992

Al- Juziyah, Ibnu Qayyim, al-Jawabal kafi limam sa'ala an al dawa' al- Syafi, Riyadh, Maktabah al- Ma'arif, 1987.

Anis Ibrahim, Al Mujamal- Wasit, Beirut, Dar al- Fikr,t.th.

Bayuni al-Siba'I, al Adab wa Al-Nushush, Dar al Nandhah al Mishr, Kairo LtBagus, Lorenz kamus filsafat, Gramedia Pustaka Utam , Jakarta,1996, Dewantara. Ki Hajar, DasarDasar Pendidikan Karya Ki Hajar Dewantara

Hijazy, 'Audh Allah Jar, Min A'lamal-Filer al-Islami Ibnu Qayyyim wa Mauqif Min al-tafkir al- Islami.

Jabir, Husen bin Muhsin bin Ali, Membentuk damaatul Muslimin, ( Terj. Abu Fahmi) dari AthThriq ila jama'ah al Muslimin, Jakarta, Gema Insani Press, 1993.

Mahmud, Ali Abdul al-Halim, Wasail al Tarbiyah inda Ikhwan Al-Muslimin. Khairo, Dar al-Wafa li-al-lhaba'ah wa al- Nasr wa al Tauzi,1998

Muthahhari, Murthada, Masyarakat dan Sejarah,( Terj. M, Hashem) dari Society and History, Bandung, Mizan, 1986.

Qahirah, Dar al-Thaba'ah al-Muhamadiyah,1996.

Sulaiman,Fatiyah Hasan, Al Muzhab al Tarbawi 'Inch Ibnu Kaldun, Kairo Dar al-Nandhah al Misr,t.,th. 